\title{
Determinants of Members' Participation Decision in Cooperatives Teff Market: The Case of Damot Gale District of Wolaita Zone, Ethiopia.
}

\author{
Tekle Leza and Adisu Kabule \\ PhD in Livelihood and Poverty Reduction, Department of Rural Development and Agricultural Extension, \\ Wolaita Sodo University,P.O.Box, 138, Wolaita Sodo, Ethiopia \\ Masters in Economic Development Policy Analysis, Department of Economics, Wolaita Sodo University, \\ P.O.Box, 138, Wolaita Sodo, Ethiopia
}

\begin{abstract}
When the issue of economic growth and development of the country is raised, one has to take into account the performance of the smallholder farmers. Reducing the challenges they are facing and utilizing their potentials can help to accelerate the agricultural sector and economic development of the country as a whole. Agricultural cooperatives are an ideal means for self-reliance, higher productivity level and promotion of agricultural development. Therefore, the major concern of this study is empirically identifying determinants of members' participation decision and level of participation in cooperatives teff market: the case of Damot Gale District of Wolaita Zone, Ethiopia. Both primary and secondary data were taken for this study. A multi-stage sampling procedure was employed to select three agricultural cooperatives and a total of 140 sample respondents taken from Damot Gale District of Wolaita Zone. Primary data pertaining to the years 2018 was collected from selected respondents through interview Schedule. Of the total respondents, about $62.8 \%$ and $37.2 \%$ were participants and non- participants in agricultural cooperatives in teff market respectively. Secondary data of the cooperatives was also taken from different journals, reviewing literature and articles. Descriptive statistics were used to compare the socio-economic, services rendered by the cooperatives and other institutional characteristics of the participants and non-participants of the cooperative marketing of teff. Testing differences between two samples were done using T-test and Chi-square test. Heckman two stage selection econometric models were employed to identify the participation decision and level of participation of teff in the one District. A total of 13 explanatory variables were included in the model in which six variables were found to be significant. Of these, six explanatory variables namely age, education of household, number of years of farmer experience, off-farm income in birr, household's land size and yield of teff were found to influence the participation decision and level of participation of teff market positively. Implications of this study are improving the continuous educating and training of members in cooperative marketing increasing the productivity and specialization of the farmers.
\end{abstract}

Keywords: Cooperative marketing, Household decision, Heckman, Wolaita.

DOI: $10.7176 / \mathrm{JESD} / 10-15-03$

Publication date: August $31^{\text {st }} 2019$

\section{INRODUCTION}

Majority of poor people in developing countries live in rural areas where their livelihood and food security are dependent on agriculture. Several studies indicated that agricultural productivity of rural people in many developing countries is decreasing due to natural resources overuse and the effect of climate change. Considerable loss also occurs with the products due to poor postharvest handling practices and limited use of appropriate postharvest technologies. (MoFED, 2005 and Tekle and Berhanu, 2015).

Moreover, the weak performance of the agricultural markets (both input and output markets) in Ethiopia has been portrayed in various studies as a major impediment to growth in the agricultural sector and the overall economy (Dawit, 2005).With an inefficient marketing system, the surplus resulting from increased production benefits neither the farmers nor the country (Alema, 2008). This is particularly important as the country is following a policy of agriculture led-industrialization and economic development where the agricultural sector is expected to produce surplus that can move to the other sectors of the economy.

The agricultural markets in Ethiopia are highly influenced by the production system itself. Most of the agricultural production is undertaken by small scale producers scattered all over the country, engaged in different agricultural enterprises without specialization, and with limited marketable surplus. (Alema, 2008) estimated that only 28 percent of total farm output was marketed. Therefore, the scattered produce in small quantity needs to be collected and assembled, graded, and transported from one market level to another. Thus, the marketing system is characterized with a long chain with many intermediaries. An intervention is required to shorten the marketing channel in order to reduce the marketing costs incurred at each level of marketing channel so that the benefits will go to the farmers (Hailu, 2007). 
The cause of success and failures of cooperatives corresponds in a building up and breaking down of cooperative identities through the process by which members and employees grow to hold the identity as their own vision.

Hence, agricultural cooperatives have been used for implementing agricultural development policies directed specifically towards smallholders of the country as smallholders' agriculture was an important component of the rural sector and its contribution has a significant place in the national economy of the country. These cooperatives were introduced as the major rural institutions to increase the productivity of teff marketing system and to promote agricultural development in the rural sector of the country's economy. They were also organized to render economic benefits such as economies of scale, market power, risk pooling, coordination of demand and supply and guaranteed access to input and output markets to these smallholders. And all these allow farmers to extend their economic power beyond the farm gate (Bernard et al, 2010).

Agricultural cooperatives provide a kind of farm supplies that will maximize returns and market farm products of the farmers based on grades and standards for quality. They are dependable source of reasonably priced supplies especially important during periods of shortage. Agricultural cooperatives introduce desirable competition that raises market prices for the farmers' products. They also expand and capture a greater share of the existing market by pooling specified grade or quality and this helps to meet the needs of large scale buyers (Alema, 2008).

In the study area of Wolaita Zone Cooperative Department Annual Abstract reveals that cooperatives provide a wide variety of services. These include grain marketing, consumer goods supply to members at reasonable prices, marketing agricultural products, supplying and distributing agricultural inputs (fertilizers, hybrid seeds and agrochemical), providing credit services, grinding mill and storage services. In addition, some cooperatives were involved in seed multiplication and distribution, veterinary medicine distribution, and technical skills development. Cooperatives have also found a clear niche in the production of high value export cereals and the packaging and distribution of fertilizer in the area (Tekle, and Berhanu,2015). The same report also justified that the total number of primary cooperative societies were 661 , of which four of them were cooperative union. Primary cooperatives were multipurpose cooperative societies (MPCs) having 137,358 total members with their annual total accumulated capital of ETB, 14,520,812 (USD, 699,798.68) (Tekle, and Berhanu, 2015).

Although cooperatives are considered as an appropriate tool of rural development they are facing critical problems, which retain them from their positive role. Some of the constraints of cooperatives are: low institutional capacity, inadequate qualified personnel, low entrepreneurship skill, lack of financial resources, lack of market information, poor members' participation in the different activities such as financing the cooperative, patronizing the business activities of the cooperatives, control and supports it (Tekle and Berhanu, 2015). Moreover, the prices of agricultural inputs are increasing from year to year and farmers are complaining on it. These multifaceted problems make very difficult the overall activities of the cooperatives in general and the agricultural input and output marketing in particular. The aforementioned problems place the farmers as usually price takers due to the fact that they have poor marketing skill and limited bargaining power. There have been attempts made by the government to improve the marketing skill and bargaining power of farmers through establishment of cooperatives and promoting other group action approaches. (Dawit, 2005).

Agricultural cooperatives are promoted by Ethiopian government as a means to increase agricultural grain marketing of farm produces and supply of farm inputs and hence agricultural development in the rural sector of the country's economy. Knowledge about their participation and factors affecting thus is of major importance for better understanding of this policy. This is why the present study focusing on identifying on members' participation decision and the level of participation in teff market through cooperatives to fill a Knowledge gaps. Besides, the study is meant to generate empirical evidences and accordingly, better understanding of development actors in their future planning and promotion of input and output marketing cooperatives.

\section{METHODOLOGY}

\subsection{Study Area}

Damot Gale District is one of the 12 District's in Wolaita Zone, Ethiopia. The total number of rural households in the District's is estimated 29,930 out of which $93.6 \%$ are men headed and $6.4 \%$ are women headed households. The total population of the District's is estimated to be 153,611 out of which $49.27 \%$ are male and $50.73 \%$ are females. The population density of the District's is 636 persons per $\mathrm{Km}^{2}$. The average household size is 5.1 and dependency ratio is 96 . The total geographical area of the District's is $22,482.4$ hectares out of which $65.80 \%$ is used to grow annual crops, and $13.3 \%$ for perennial crops. The rest of the land is used for grazing, forest, degraded and small portion of land for other communal purposes. The District's is predominantly rural, and depends on agriculture (WZFEDD, 2016). The major economic activity is rain fed farming. Major crops grown in the District's include cereals, pulses, fruits, root crops and cash crops like coffee. Wheat, haricot bean/kidney bean, teff and maize are the dominant cereal crops grown in the District's. However, the area is known for its low productivity due to land scarcity, erratic rainfall and prevalence of pests. As a result, income from non-farm and off-farm activities is the second most important source of livelihood. Especially, small trading plays an important 
contribution in generating income. Apart from trading, income from daily labor and seasonal workforce movement during harvest time is another source of income to the farmers.

\subsection{Sampling Techniques and Sample Size Determination}

In the study area, farming households were responsible for making day to day decision on farm activities. Thus, households were the basic sampling unit. A multi-stage sampling technique was used to generate the required primary data. At the first stage, Damot Gale District's was selected purposively because one of the largest numbers of multipurpose cooperatives found in the Zone. In the second stage, out of seven multipurpose cooperatives, three multipurpose cooperatives (Wandara, Ade-Charake and Buge) were selected by using simple random sampling techniques. Thirdly, the target population or the total households of multipurpose cooperatives (MPCOs) were heterogeneous in nature the sample draw from these target households MPCOs households were participate and non- participate in cooperatives market. The nature of heterogeneous, stratified sampling techniques was employed to determined numbers of participate and non- participate households. Sample size was determined by using simplified formula provided by (Kothari, 2004). Based on simplified formula provided by Kothari 140 household were determined. A probability proportion to size was employed to determine sample size from each multipurpose cooperative and finally each household was selected by using systematic sampling without replacement technique.

$$
\mathrm{n}=\frac{\left(Z^{2}\right)}{\left(e^{2}\right)} \frac{(p q N)}{(N-1)+Z^{2} p q}=140
$$

Where, $\mathrm{n}=$ sample size, $\mathrm{N}=$ population and $\mathrm{e}=$ margin error $=0.08, \mathrm{Z} \propto / 2$ : normal reduced variable at 0.08 level of significance $\mathrm{Z}$ is 1.96 and $\mathrm{p}+\mathrm{q}=1$, population reliability (or frequency estimated for a sample size $n$ ), $p$ is 0.63 and $\mathrm{q}$ is 0.37 .

Table 1 Distribution of sample households included in the survey by Villages

\begin{tabular}{llcccc}
\hline District & MPCOs & Total & \multicolumn{2}{c}{ Sample Size households } & Total \\
\cline { 3 - 6 } & & & Participate & Non-participate & 63 \\
\hline Damot & Ade-Charake & 270 & 40 & 23 & 59 \\
Gale & Wandara & 254 & 37 & 22 & 18 \\
& Buge & 76 & 11 & 7 & 140 \\
\hline Total & & 600 & 88 & 52 & \\
\hline
\end{tabular}

Source: Damot Gale District of Cooperative Office (2018)

\subsection{Data Sources and Methods of Data Collection}

Quantitative data was collected from primary and secondary sources. Quantitative data from primary sources were collected through household survey. The relevant data was collected from 140 sample households. An interview schedule was prepared in English and translated into local language Wolaytegna to ease communication during the data collection. The interview schedule was pre-tested before going to actual data collection and making necessary corrections. Four enumerators were recruited based on their proficiency in communicating local language, educational background and prior exposure to similar works. Training was given to enumerators on the content of the interview schedule and procedures to follow while conducting interview. The survey focused on economic, demographic, institutional and psychological factors of cooperative members. Secondary data was collected from different sources such as Wolaita Zone cooperative promotional department, Damot Gale district cooperative office, Journals, and Central Statistical Authority (CSA) publications, published and unpublished documents, etc.

\subsection{Methods of Data Analysis}

Two types of data analysis methods, namely descriptive statistics refers to the use of ratios, percentages, means and standard deviations. Chi-square and t-test were used in the process of comparing socio economic, demographic and institutional characteristics of households where as econometric models (Heckman two stage selection models) were used to analyze hypothesized variables the study area. In order to analyze determinants of members participate decision and the level of participation in teff market. Heckman two-stage selection models were used. Specifications of the models used to identify determinants follow the selectivity models widely discussed in the participation decision and level of participation literature (Heltberg and Trap, 2002); (Bellemare and Barrett, 2006).

In selectivity models, the decision to participate can be seen as a sequential two-stage decision making process. In the first-stage, households make a discrete choice whether or not to participation decision in teff markets. In the second-stage, conditional on their level of participation in teff market, households make continuous decision on the quantity of supply. In the first-stage, standard probit model, which follows random utility model and specified as Wooldridge (2002) was used:

$$
\begin{aligned}
& \mathrm{Y}^{*}=\mathrm{Z}^{\prime} \boldsymbol{\alpha}+\boldsymbol{E}_{\mathrm{I}} \\
& \mathrm{Y}=1 \text { if } \mathrm{Y}^{*}>0
\end{aligned}
$$


$\mathrm{Y}=0$ if $\mathrm{Y}^{*} \leq 0$

Where, $\mathrm{Y}^{*}=$ is a latent (unobservable) variable representing household discrete decision whether to participate in teff market or not. $\boldsymbol{Z}^{\prime}=$ is a vector of independent variables hypothesized to affect household decision to participate members' decision in agricultural cooperatives in teff market $\alpha=$ is a vector of parameters to be estimated. $\boldsymbol{E}_{1}=$ is normally distributed disturbance with mean (0) and standard deviation of (1), and captures all unmeasured variables. $\mathrm{Y}=$ is a dependent variable which takes on the value 1 if a household participate in agricultural cooperatives in-farm level of markets and 0 otherwise. Since the probit parameter estimate does not show by how much a particular variable increases or decreases the likelihood of members' participating decision and the level of participation in teff market through cooperatives independent variables on probability of a household to participate were considered. For continuous independent variables, marginal effect was calculated by multiplying coefficient estimate by standard probability level of participation by holding other independent variables at their mean values. The marginal effect of dummy independent variables was analyzed by comparing probabilities of that result when the dummy variables take their two different values ( 1 if participated and 0 otherwise) while holding all other independent variables at their sample mean values Wooldridge, (2002). Finally, the log likelihood function which is maximized to obtain parameter estimates and corresponding marginal effects was given as:

$\operatorname{Ln} \quad L\left(\frac{\alpha}{Y}, Z\right)=\sum_{y=1} \ln \left(\Phi\left(Z^{\prime} \alpha\right)\right)+\sum_{y=0} \ln \left(1-\Phi\left(Z^{\prime} \alpha\right)\right)$

Conditional on participation, variables determining on members' participation decision and the level of participation in teff market through cooperatives were modeled using second-stage Heckman selection model (Heckman, 1979). The Heckman selection equation is specified as

$$
\begin{aligned}
& \mathrm{Z}_{\mathrm{i}}^{*}=\mathrm{W}_{i}^{\prime} \boldsymbol{\alpha}+\boldsymbol{E}_{2} \\
& \mathrm{Z}_{\mathrm{i}}=\mathrm{Z}_{i} * \text { if } Z_{i} *>0 \\
& \mathrm{Z}_{\mathrm{i}}=0 \text { if } Z_{i} * \leq 0
\end{aligned}
$$

Where, $\mathrm{Zi} *=$ latent variable representing desired or optimal value of teff market added or sold which is observed if $\mathrm{Zi}^{*}>0$ and unobserved otherwise. $\mathrm{Z}_{i}=$ is the observed value of teff added or sold. $\mathrm{W}_{i}{ }^{\prime}=$ vector of covariates for unit i for selection equation which is a subset of $Z^{\prime} \alpha=$ vector of coefficients for selection equation. $\mathcal{E}_{2}=$ random disturbance for unit i for selection equation. One problem with the two equations (2 and 4$)$ is that the two-stage decision making processes are not separable due to unmeasured variables determining both discrete and continuous decision there by leading to correlation between errors of the equations. If the two errors are correlated, the estimated parameter values on variables members' participation decision and the level of participation in teff market through cooperatives supply is biased (Woodridge, 2002). Thus, we need to specify a model that corrects for selectivity bias while estimating determinants of level of participation and quantity of supply. For this purpose, in the first-step, Mills ratio was created using predicted probability values obtained from the first-stage probit regression of participation decision. Then, in the second-step, Mills ratio was included as one of the independent variables in level of participation and quantity of supply regression. Thus, level of participation and quantity of supply equation with correction for sample selection bias becomes:

$\mathrm{V}=\mathrm{W}_{\mathrm{i}} \alpha+\lambda\left(\frac{\phi(W i \alpha)}{\Phi(W i \alpha)}\right)+\varepsilon_{3}$

Where, $\phi(.) / \Phi()=$. is the Mills ratio. $\lambda=$ is the coefficient on the Mills ratio.

$\phi=$ denotes standard normal probability density function. $\Phi=$ denotes standard cumulative distribution function. $\mathcal{E}_{3}=$ is not correlated with $\mathcal{E}_{1}, \mathcal{E}_{2}$ and other independent variables. Under the null hypothesis of no sample selection bias $\lambda$ is not significantly different from zero. $\mathrm{V}=$ is level of participation and quantity of supply (quintals). 
Table 2. Summary of Explanatory variables, Measurement and Expected sign

\begin{tabular}{|c|c|c|c|}
\hline Variables & Types & Measurement & Sign \\
\hline AGE & Continuous & Years & + \\
\hline FASI & Continuous & Number & - \\
\hline EDU & Continuous & School years & + \\
\hline NYOM & Dummy & Years & + \\
\hline OFFI & Continuous & Years & + \\
\hline HEHL & Continuous & Hectors & + \\
\hline TLU & Continuous & TLU & + \\
\hline FAREX & Continuous & years & + \\
\hline DIEXS & Continuous & $\mathrm{Km}$ & + \\
\hline ACTC & Dummy & $1=$ accessed credit, $0=$ otherwise & + \\
\hline MRTINF & Dummy & $0=$ Not Good, $1=$ Good & + \\
\hline YIELD & Continuous & $\mathrm{Q} / \mathrm{ha}$ & + \\
\hline THH & Dummy & $1=$ participate in training $0=$ otherwise & + \\
\hline
\end{tabular}

\section{RESULTS AND DISCUSSION}

\subsection{Descriptive Analysis}

Out of the sample farmers interviewed, $62.8 \%$ of the farmer's marketed teff through the cooperative (participants of the cooperative marketing for their teff) while $37.2 \%$ of the farmers didn't market teff through the cooperatives (non-participants of the cooperative marketing for their teff) in the year 2018.

Age of household (AGE): The average age of the sample farmer's participants of cooperatives was about 47 years. The corresponding average age figure for the cooperative participants and non- participants was about 36.5 and 33.1 years with standard deviation of 7.3 and 6.5 years respectively. The participants were more aged than the non- participants. There was significant mean difference between cooperative participants and non- participants at one percent probability level $(\mathrm{t}=2.73 ; \mathrm{P}=0.007)$. Table 3

Family size of household (FASI): It refers to the total members of cooperatives participants and non- participants' household measured in adult equivalent. It was assumed that households with larger size consume more of what was produced and little would remain to be marketed. The corresponding figure for the non- participants on average was 5.1 persons with the standard deviation of 1.6 whereas the average mean of the participants was 5.5 with standard deviation 1.5. The average total family size of the sample households was 5.34 persons with standard devotion was 1.53 .The averages household size of Wolaita Zone (5.1) was lower than average finding of this survey(5.34). This result agrees with the findings of (Tekle and Berhanu 2015). It was expected to have negative effect on households' decision to use in the agricultural cooperative marketing. The independent t-test between participants and non- participants shows statistically significant mean difference at ten percent probability level $(\mathrm{t}$ $=1.81 ; \mathrm{P}=.072$ ).

Number of years farming experience (FAREX): As to their farming experience, the average years of farm experience of participant and non-participant farmers was 11.78 and 9.15 years with standard deviation of 6.13 and 4.08 respectively. The participants have more years of farming experience than the non-participants. The ttest between participants and non- participants shows significant mean difference at one percent probability level $(\mathrm{t}=2.75 ; \mathrm{P}=.007)$. Table 3

Off-farm income in Birr (OFFI): Out of the total households interviewed, $90.43 \%$ involved off-farm activities. The cooperative market participant and non-participant generated an average annual income of birr 6109.80 and 4755.7 with standard deviation of 3615 and 4287 birr respectively. The cooperative market participant had received more income than non-participant. The independent t-test between participants and non- participants shows statistically significant mean difference at one percent probability level $(\mathrm{t}=2.75 ; \mathrm{P}=007)$. Table 3

Households number of livestock (TLU): The participants and non- participants average livestock holding size were 1.47 and $1.36 \mathrm{TLU}$, respectively and the overall average for the sample was $2.83 \mathrm{TLU}$. This shows that the average livestock holdings of participants was greater than that of non- participants. This means participants of cooperative members were in better position with respect to livestock holding than non- participants of cooperatives. According to independent t- test, the no statistically mean difference in livestock holding between participants and non- participants. $(\mathrm{t}=1.217, \mathrm{p}=0.226)$. Table 3

Distance from the extension services (DIEXS): Members' participant and non-participant of cooperative marketing, who live relatively nearer to extension office, have more chance to participate in marketing of teff. This could be due to the fact that it was more convenient to extension services and cooperative promoters in giving training and support than distant households. Furthermore, the cooperative promoting of teff focus in helping in creation of awareness may be concentrated on the nearest members to extensions office because currently one cooperative promoter has responsibility for one village. This finding reveals that as distance increases by a minute, member participation decision in agricultural cooperative marketing on average 1.72 percent and 0.44 percent 
standard deviation respectively. This study result coincides with the findings of (Tekle and Birhanu, 2015). Table 3

Households land size in hectors (HEHL): Land is one of the most important determinants of agricultural production. It plays a central role in producing crops and rearing livestock. Moreover, access to land offers a privilege to utilize agricultural extension services and new agricultural inputs. Findings revealed that the average land holding in the study area was 1.43 ha with standard deviation of 0.64 . Moreover, the corresponding average land holding size for participants and non-participants was 0.71 and 0.72 hectares with the standard deviation of 0.30 and 0.30 hectares, respectively. The t-test reveals no significant mean difference in land holdings between participants and non-participants. $(\mathrm{t}=0.108, \mathrm{p}=0.914)$. Table 3

Major crops produced in the district are among the most known agriculturally rich district and they are popular in farming activities especially in crop production. The sample farmers grew cereals and pulses as main food crops and for sale to meet their cash requirements. Teff was produced by the sample farmers for the purpose of both consumption and sale. The average area used by the sample farmers for the production of teff was 0.45 hec. The sample participant farmers that marketed teff through the cooperatives used an average area of 0.49 hec. The corresponding figure for the non-participants was 0.39 hec. Table 4

Table 3: The Mean of Output Marketing by Cooperative members

\begin{tabular}{lllll}
\hline Variables & Participants(n=88) & Non-participants $(\mathbf{n}=\mathbf{5 2})$ & Total $(\mathbf{n}=\mathbf{1 4 0})$ & t-value \\
\cline { 2 - 4 } & Mean (SD) & Mean (SD) & Mean (SD) & \multirow{2}{*}{$2.73^{* * *}$} \\
\hline AGE & $36.5(7.3)$ & $33.1(6.5)$ & $47(12.8)$ & $1.81^{*}$ \\
FASI & $5.5(1.5)$ & $5.1(1.6)$ & $5.34(1.53)$ & $2.75^{* * *}$ \\
FAREX & $11.78(6.13)$ & $9.15(4.08)$ & $10.8(5.3)$ & 1.966 \\
OFFI & $6109.8(3615)$ & $4755.7(4287)$ & $5258.6(3919.1)$ & 0.108 \\
HEHL & $0.71(0.34)$ & $0.72(0.30)$ & $1.43(0.64)$ & 1.217 \\
TLU & $1.47(0.43)$ & $1.36(0.56)$ & $2.83(0.99)$ & $3.001 * * *$ \\
DIEXS & $1.72(0.44)$ & $1.48(0.50)$ & $1.65(0.47)$ & \\
\hline
\end{tabular}

Source: Household Survey (2018)

Table 4. Distribution of the sample farmers by the area of major crops+

\begin{tabular}{llll}
\hline Types of & Participants & Non- participants & Total \\
\cline { 2 - 4 } crops & Area in hec(SD) & Area in hec(SD) & Area in hec(SD) \\
\hline Teff & $0.49(0.13)$ & $0.39(0.30)$ & $0.45(0.37)$ \\
Maize & $0.18(0.22)$ & $0.18(0.30)$ & $0.26(0.22)$ \\
Haricot bean & $0.09(0.14)$ & $0.10(0.17)$ & $0.09(0.15)$ \\
\hline
\end{tabular}

Source: Household Survey (2018)

Access to credit(ACTC): Access to rural credit was played a vital role in improving productivity of resources through purchasing agricultural cooperatives marketing of participants and non- participants inputs, filling consumption gap when it occurs, and availing resources for meeting social obligations, etc. Out of the sample farmers, $57 \%$ received credit from these sources for the purpose of purchase agricultural inputs, fattening, contracting land and ox and other social obligations whereas $43 \%$ not accessed credit service. The $\chi 2$-test shows that there was significant difference between cooperative participants and non- participants in getting credit services. $(\chi 2$-value $=1.516, \mathrm{P}=0.012)$. Table 5

Training of household (THH): Continuous training of the farmers help equip the farmers with the skill, knowledge and confidence to enable them use, participate in and control the cooperative more effectively. Out of the sample farmers, 34 percent got education/training from their cooperative in prior year whereas 66 percent figure did not got farming services. The $\chi 2$-test result reveals that no significant association between cooperative participants and non-participants in cooperative market. $\left(\chi^{2}\right.$ - value $\left.=1.49, p=0.13\right)$. Table 5

Access to market information (MKTINF): Household's members' participation decision and level of participation in teff market demand, supply and price information were better access but 95.7 percent of household's didn't get access to market information. Poorly integrated markets may convey inaccurate price information leading to inefficient product movement. Better access to market information significantly raised probability of market participation of households. Table 5 . 
Table 5. The frequency of Output marketing by Cooperative members

\begin{tabular}{|c|c|c|c|c|c|c|c|c|}
\hline \multirow[b]{2}{*}{ Variables } & \multirow[t]{2}{*}{ Categories } & \multicolumn{2}{|c|}{ Participants $(n=88)$} & \multicolumn{2}{|c|}{ Nonparticipants(n=52) } & \multicolumn{2}{|c|}{ Total $(n=140)$} & \multirow[t]{2}{*}{$\chi^{2}$-value } \\
\hline & & Freq & $\%$ & Freq & $\%$ & Freq & $\%$ & \\
\hline & Accessed & 46 & 52 & 34 & 65 & 80 & 57 & $1.516^{*}$ \\
\hline ACTC & Not & 42 & 48 & 18 & 35 & 60 & 43 & \\
\hline \multirow{2}{*}{ THH } & Yes & 31 & 35 & 17 & 33 & 48 & 34 & 1.495 \\
\hline & No & 57 & 65 & 35 & 67 & 92 & 66 & \\
\hline \multirow[t]{2}{*}{ MKTINF } & Good & 82 & 93 & 52 & 100 & 134 & 4.3 & $1.937 *$ \\
\hline & Not & 6 & 7 & 0 & 0 & 6 & 95.7 & \\
\hline \multirow[t]{4}{*}{ EDU } & Illiterates & 17 & 19.32 & 4 & 7.69 & 21 & 15 & \\
\hline & $1-8$ & 9 & 10.23 & 6 & 11.54 & 15 & 10.71 & $6.66 * *$ \\
\hline & $9-12$ & 36 & 40.90 & 17 & 32.69 & 53 & 37.86 & \\
\hline & $>=$ College & 26 & 29.55 & 25 & 48.08 & 51 & 36.43 & \\
\hline
\end{tabular}

Source: Household Survey (2018)

\subsection{Determinants of Teff market participation Decision and Level of Participation:}

Soundness of the model was established by Wald test. The chi-square of the model regression in the District indicated overall goodness of fit (showing a strong explanatory power) of the model with statistical significance at a probability of one per cent. It clearly shows the binary dependent variable: one (1) if the household participates cooperative marketing and zero (0) otherwise. The model correctly predicted $81 \%$. The Wald test of the cooperative marketing $\chi 2(13)=47.04 \%$. The model chi-square tests applying appropriate degrees of freedom indicate that the overall goodness of fit for the Heckman selection model is statistically significant at a probability of less than $1 \%$. This shows that jointly the independent variables included in selection model regression explained amount of supply of Teff. As a result the model fulfilled conditions of good fit. Table 6 presents the probit model's estimates underlying the Heckman-Two-Step estimation procedure. The model results indicated that out of 13 explanatory variables, six variables explained probability of Teff market participation. These variables are age of the household, education of household head, number of years of farmer experience, off/non-farm income in birr, household's land size in hectare and yield of teff. Table 6

Age of household (AGE): age of household head had positive and significant impact on Teff market participation. The positive and significant relationship between the two variables indicates that young aged household heads could use improved inputs to produce large amount of Teff that could help in increasing probability of market participation. The result of this study coincides with the findings of (Tshiunza et al. 2001). The marginal effect indicates that probability of participating in Teff market increases by 0.004 as age of household head increases by a year. Table 6

Education of household head (EDU): As expected, level of education was positively influencing participation decision and level of participation in teff marketing at less than 5 per cent probability level. The marginal effect indicated that an increase in educational level by one unit leads to increase probability of participation decision and level of participation in teff market by 0.004 and 0.079 percent respectively at ceterius paribus. This implies that educated people show higher tendencies to participate in cooperative marketing than non-participant. The higher the education level, the better would be the knowledge of the farmer towards the cooperative and acquire news and education about the benefits of the cooperative of teff easily. Hence, those farmers with higher level of education are in a better position to know the benefits of cooperative and are more likely to market their teff through the cooperatives. This result agrees with findings of (Jemal et al., 2008) and (Daneil et al., 2006). Table 6 and 7

Family size of household (FASI): As prior expectation, household size had negative and significant effect on amount of marketable supply of Teff less than at 10 per cent probability level. The negative and significant coefficient of the variable depicts that the larger the household size, the more amount of Teff required for domestic consumption and the lesser the amount left out for markets. The finding is consistent with findings of (Edmeades, 2006) and (Berhanu and Moti, 2010). This implies that keeping other explanatory variables constant, increase in household size by one member results in 0.068 amount decrease in quantity of Teff supply. It was suggested that interventions aimed at promoting family planning amongst farm communities can contribute to commercial transformation of subsistence agriculture. Table 6

Off-farm income in Birr (OFFI): As expected, Off-farm income had positive and significant effect on participation decision and the amount of marketable supply of teff at less than $5 \%$ probability level. Marginal effect indicated that one birr increases in income from off-farm leads increase the participation decision and level of participation in teff marketing through cooperatives by 0.065 and 0.907 respectively at ceterius paribus. Implies households have inadequate on-farm income they often look for other sources of income. So this income has a great support for farming population to fulfill their obligation. Moreover, the income raised from such activities help the members not to sale their crops produce like Teff, immediately after harvest at cheap price. Rather the 
trend of their involvement in buying primary agricultural cooperative marketing increases on the contrary. This result also confirms the finding of (Martey et al. 2012). Table 6 and 7

Household's land size in hectare (HEHL): Land size had a positively and significantly influenced household participation decision and level of participation at less than $10 \%$ and $5 \%$ probability level respectively. Marginal effect indicated that each additional hectare of land increases the probability of participation decision and level of participation of teff marketing through the cooperatives by 0.06 and 0.296 respectively. The implication is that farmers with larger land size in hectares more used the cooperative as marketing of teff than farmers with smaller land size in hectare. (Jemal et al., 2008) also found that farmer land size in hectare influences the usage of the cooperative teff marketing. Table 6 and 7

Number of years of farmer experience (FAREX): As expected, number of years of farmer experience in cooperative marketing of teff was positively influenced the participation decision at 5 per cent probability level. Marginal effect indicated that a one year farmer experience increases the probability of marketing of teff through the enhanced by 0.003 percent. Farmer having longer years of farm experience are in a better position to know the benefits of the cooperative than farmers with shorter years (Tekle and Berhanu, 2015) and (Gebremedhin, and Hoekstra, 2007). Table 6 and 7

Yield of teff (YIELD): As expected, yield influenced positively and significantly participation decision and level of participation at less than $1 \%$ probability level. The marginal effect shows, keeping other variables constants, an increase in the participation decision and level of participation by one unit's increases quantity of Teff supply by 0.023 and 0.131 of cooperative marketing. The result confirms the finding of (Edmeades., 2006). Table 6 and 7

LAMDA: the coefficient of Mills ratio (Lamda) in the Heckman two-stage estimation was significant at the probability of less than $5 \%$. This indicates sample selection bias, existence of some unobservable household characteristics determining likelihood to participate in teff market and there by affecting quantity of supply.

Table 6 First-stage probit estimation results of determinants of probability of teff market participation.

\begin{tabular}{|c|c|c|c|}
\hline \multirow[t]{2}{*}{ Symbol } & Coefficient & $\begin{array}{l}\text { Marginal } \\
\partial P(Y=1 / X) \\
\end{array}$ & \multirow[t]{2}{*}{$\mathbf{P}>|\mathbf{z}|$} \\
\hline & \multicolumn{2}{|r|}{$\partial X$} & \\
\hline Constant & $-0.141(0.442)$ & & 0.749 \\
\hline AGE & $0.015(0.007)$ & $0 . \overline{004(0.002)}$ & $0.048 * *$ \\
\hline FASI & $-0.046(0.031)$ & $-0.012(0.008)$ & 0.139 \\
\hline EDU & $0.079(0.032)$ & $0.004(0.004)$ & $0.013 * *$ \\
\hline NYOM & $0.174(0.104)$ & $0.047(0.029)$ & 0.096 \\
\hline OFFI & $0.907(0.365)$ & $0.065(0.042)$ & $0.013 * *$ \\
\hline HEHL & $-0.228(0.117)$ & $0.061(0.033)$ & $0.052 *$ \\
\hline TLU & $-0.053(0.088)$ & $-0.014(0.024)$ & 0.550 \\
\hline FAREX & $0.014(0.006)$ & $0.003(0.001)$ & $0.037 * *$ \\
\hline DIEXS & $0.191(0.165)$ & $0.050(0.044)$ & 0.248 \\
\hline ACTC & $3.265(1.892)$ & $0.02(0.01)$ & 0.084 \\
\hline MRTINF & $-0.123(0.179)$ & $-0.032(0.045)$ & 0.493 \\
\hline YIELD & $0.086(0.029)$ & $0.023(0.006)$ & $0.003 * * *$ \\
\hline $\mathrm{THH}$ & $-0.064(0.183)$ & $-0.017(0.0481)$ & 0.724 \\
\hline \multicolumn{4}{|c|}{ Number of observations $=140$} \\
\hline Log pseudo-likelihood & $=-193.29 * * *$ & & \\
\hline Wald Chi square (13) & $=47.04$ & & \\
\hline Pseudo $\mathrm{R}^{2}$ & $=0.168$ & & \\
\hline Observed probability & $=0.72$ & & \\
\hline Predicted probability & $=0.81$ & & \\
\hline
\end{tabular}

Source: Own computation from the data of 2018 . Figures in parenthesis are robust standard errors. ${ }^{* * *},{ }^{* *}$, and ${ }^{*}$ indicate statistical significance at $1 \%, 5 \%$, and $10 \%$, respectively. 
Table7 Results of second-stage Heckman selection estimation of determinants of quantity of teff supply

\begin{tabular}{llll}
\hline \multicolumn{1}{c}{ Symbol } & Coefficient & Standard error & $\mathbf{P}>/ \mathbf{z} /$ \\
\hline Constant & -0.081 & 0.440 & 0.853 \\
AGE & 0.011 & 0.007 & 0.127 \\
FASI & -0.068 & 0.036 & $0.059^{* *}$ \\
EDU & 0.079 & 0.032 & $0.013^{* *}$ \\
NYOM & -0.0314 & 0.019 & 0.111 \\
OFFI & 0.907 & 0.365 & $0.013^{* *}$ \\
HEHL & 0.296 & 0.112 & $0.009 * *$ \\
TLU & 0.079 & 0.072 & 0.281 \\
FAREX & -0.012 & 0.007 & 0.098 \\
DIEXS & 0.076 & 0.167 & 0.649 \\
ACTC & 0.112 & 0.059 & 0.165 \\
MRTINF & -0.092 & 0.188 & 0.623 \\
YIELD & 0.131 & 0.025 & $0.000^{* * *}$ \\
THH & 0.129 & 0.080 & 0.111 \\
LAMDA & 0.046 & 0.023 & $0.05^{* *}$ \\
\hline
\end{tabular}
Number of observations $=140$
Wald Chi square (13) $=47.04$
Log pseudo-likelihood $=-193.29 * * *$
Wald $\operatorname{chi}^{2}(13) \quad=67.12 * * *$
Rho $\quad=0.531$
Sigma $=0.086$

Source: Own computation from the data of 2018 . ***,**, and * indicate statistical significance at $1 \%, 5 \%$, and $10 \%$, respectively.

\section{CONCLUSION AND RECOMMENDATION}

The study was conducted to identify determinants of cooperative member participation and level of participation teff marketing at Damote Gale District of Wolaita Zone in Ethiopia. Both primary and secondary data were taken for this study. A multi-stage sampling procedure was employed to select three agricultural cooperatives and a total of 140 sample respondents taken from Damot Gale District of Wolaita Zone. Primary data pertaining to the years 2018 was collected from selected respondents through interview Schedule. Of the total respondents, about $62.8 \%$ and $37.2 \%$ were participants and non- participants in agricultural cooperatives in teff market respectively. Secondary data of the cooperatives was also taken from different offices, journals, reviewing literature and articles.

A total of 13 explanatory variables were included in the model in which six variables were found to be significant. Of these, six explanatory variables namely age, education of household, number of years of farmer experience, off-farm income in birr, household's land size and yield of teff were found to influence the participation decision and level of participation of teff market positively. Members' participation decisions and level of participation in cooperative marketing are great important for their significant positive impacts to cooperative members life. This has been observed from economic analysis and findings of this study. These results have important policy implications to be recommended.

- Development practitioners should create awareness among members and encourage the use of family planning in order to limit household size. This can be achieved through integrated health and education services.

- Education level of household was positively influencing the members' participation decisions and the level of participation of teff marketing through cooperatives. Therefore, effort should be geared towards increasing qualified manpower in cooperatives marketing of teff, upgrading management capacity of cooperative management body (Board of directors, other employed workers and members) through education and information dissemination in cooperative teff marketing.

- One of the aims of establishing cooperatives in the rural area is to increase the efficiency of marketing system. For this to be so, first the farmer has to get good yield of teff i.e. produce surplus. The cooperatives are performing a significant role in increasing the productivity of the farmers by supplying farm inputs especially fertilizer in credit. Other development partners should also give due emphasis with regard to this issue. Appropriate and effective extension services should be continued in the area in order to enhance the productivity of the farmer. The other issue to be concerned is the specialization of the farmer. As the cooperatives in the study area encourage and purchase teff, farmers should be encouraged to produce this item. 
- Above all, changing the attitudes of the farmers towards their cooperatives was a crucial factor in improving the members' participation in the study area. Most of the sample farmers need only immediate economic advantages from the cooperatives i.e. getting hybrid seed and fertilizers from cooperatives as marketing of teff. They don't pay attention to the sum total of the different advantages they can get in the long-run if they actively use strengthened cooperatives as marketing of teff.

- The concerned bodies should create awareness about cooperative as marketing of teff and the primary agricultural development it can bring to the area in the long-run. Continuous education and enlightenment of the farmer's households will have a positive impact on their participation decision and level of participation towards the cooperatives as marketing of teff.

\section{REFERENCES}

Alema.W. Analysis of role of cooperatives in agricultural input and output marketing in the case of Southern zone of Tigray Ethiopia. Unpublished M. Sc. Thesis, submitted to Department cooperative development Mekelle University, (2008). 147P

Bellemare, M.F., and C.B. Barrett. 2006. "An Ordered Tobit Model of Market Participation: Evidence from Kenya and Ethiopia.” American Journal of Agricultural Economics 88(20):324-337

Berhanu Gebremedhin and Moti Jeleta, (2010). Commercialization of smallholders: Does market orientation translate into market participation? Improving Productivity and Market Success (IPMS) of Ethiopia farmer's project working paper 22. Nairobi Kenya, ILRI

Bernard, T., D. Spielman, A.S. Taffesse, E. Gabre-Madhin. 2010. Cooperatives for Staple Crop Marketing: Evidence from Ethiopia. (Vol. 16). Washington, DC: Intl Food Policy Res Inst.

Daniel Belay, (2006). Performance of primary agricultural cooperatives and determinantsf members' decision to use as marketing agent in Adaa Lliben and Lume districts MSc. thesis in agricultural Economics, Alemaya University, Ethiopia.

Dawit Alemu, (2005). The status and challenges of agricultural marketing in Ethiopia, MelkassaAgricultural Research Center, EARO Paper presented at a panel discussion organized bythe Ethiopian Association of Agricultural Professionals (EAAP), Addis Ababa, Ethiopia

Edmeades, S., (2006). Varieties, attributes and marketed surplus of a subsistence crop: Banana in Uganda. Paper presented at international association of agricultural economists association, Gold Coast, Australia, August 12-18.

Gebremedhin, B., and Hoekstra, D, (2007). Cereal Marketing and Household Market Participation in Ethiopia: The Case of Teff, Wheat and Rice. International Livestock Research Institute (ILRI) Addis Ababa, Ethiopia. AAAE Conference Proceedings, 243-252.

Hailu Adugna (2007). "An Assessment of the Role of Cooperatives in Local Economic Development." Unpublished M.A thesis. Addis Ababa University.!37p

Heckman, J.J. 1979. “Sample Selection Bias as aSpecification Error.” Econometrica 47:931-59.

Jemal M. Analysis of the Role of Cooperatives in Agricultural Input and Out Put Marketing in Eastern Zone, M. Sc Thesis, Mekelle Unversity,(2008).

Kothari, C.R. (2004). Research Methodology Methods \& Techniques 2nd Edition. New Delhi, India. New Age International (P) Limited.

Martey, E., Ramatu, M.A., and John, K.M.K, (2012). Commercialization of smallholder agriculture in Ghana: A Tobit regression analysis. African Journal of Agricultural Research, 7(14):2131-2141.

MoFED.Ministry of Finance and Economic Development Sustainable Development and Poverty Reduction Program, Addis Ababa, Ethiopia; (2005).

Tekle, L. and Berhanu, K. Determinants of Rural Farm Household Food Security in Boloso Sore District of Wolaita Zone in Ethiopia. Asian Journal of Agricultural Extension, Economics \&Sociology 5(2): 57-68, (2015); Article no.AJAEES.2015.039ISSN: 2320-7027; (2015).

Tshiunza, M., J. Lemchi and A. Tenkouano, (2001). Determinants of market production of cooking banana in Nigeria. African Crop Science Journal 9(3): 537-547.

Wooldridge, J. M. (2002), “Asymptotic Properties of Weighted M-Estimators for Standard Stratified Samples." Econometric Theory 17, 451-470.

WZOCPD.Wolaita Zone Cooperative Promotion Development, Data Collection, organization and Work Process. Annual Abstract, Wolaita Sodo; (2014). 